\title{
The present and future for gene and viral therapy of directly accessible prostate and squamous cell cancers of the head and neck
}

\author{
James S Norris', Kristi L \\ Norris, David H \\ Holman, Abmed El- \\ Zawabry, Thomas E \\ Keane, Jian-yun Dong, \\ Mahvash Tavassoli \\ ${ }^{\dagger}$ Author for correspondence \\ Department of Microbiology \\ and Immunology, Medical \\ University of South Carolina, \\ 173 Ashley Avenue, \\ Charleston, SC 29425, USA \\ Tel.: +18437927915 \\ Fax: +18437924882 \\ norrisjs@musc.edu
}

Keywords: acid ceramidase, adenoviral-mediated $p 53$ gene therapy, apoptosis, ceramide, Fas ligand, gene therapy, ONYX 015, probasin Newcastle disease virus, prostate cancer, prostatespecific antigen, replication competent adenovirus, sphingolipids, squamous cell cancer of the head and neck

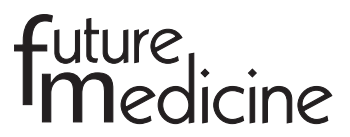

\begin{abstract}
Gene therapy has been in a continuous evolutionary process since the first approved trial occurred in 1990 at the National Institute of Health. In the USA, as of March 2004, there were 619 approved gene therapy/transfer protocols and 405 of these were for cancer treatment. Another 294 trials are in progress worldwide, with most concentrated in Europe. However, cancer gene therapy is in its relative infancy when compared with the well-established use of chemo-radiotherapy for treating cancer. As the field develops it is becoming clear that using gene therapy in conjunction with established chemo-radiotherapy approaches is yielding the best results. This concept shall be reviewed in the context of the status of the field, and a future direction based on a combination of gene therapy with small molecule modification of sphingolipid metabolism shall be discussed.
\end{abstract}

\section{The potential \& the problems}

With the availability of the human genome sequence and continuing development of bioinformatic tools to analyze it, our understanding of the causes of cancer is rapidly expanding. One of the main objectives of this research is to identify specific genetic aberrations and develop new therapeutic strategies and compounds that directly target both genetic and biochemical causes of malignant transformation. With respect to cancer gene therapy, treatment options have already greatly expanded. However, our ability to eradicate cancer by delivering a corrective signal to every cell in the tumor remains problematic. Thus, studies on the delivery of therapeutic genes and how to amplify their therapeutic efficacy in combination with drugs or radiation are urgently required.

This review describes gene therapy approaches using $p 53$ gene replacement or adenoviral vectors that replicate preferentially in cancers in both mono- and combination therapy formats. A discussion of the stress response and sphingolipid metabolism in tumor cells is included. The authors conclude by contemplating the future potential of treatments that overcome the failure in $41.6 \%$ of prostate cancer to downregulate ceramide, a major tumor suppressor lipid, by using small molecule inhibitors of acid ceramidase combined with Fas ligand (FasL) gene therapy.

\section{p53 \& its family members}

The most frequent genetic alterations in head and neck squamous cancer cells (HNSCC) are mutations in the $p 53$ tumor suppressor gene [101]. $p 53$ is a sequence-specific transcriptional activator that plays an important role in the regulation of cell cycling, apoptosis and DNA repair $[1,2] . p 53$ becomes stabilized in response to DNA damage and can trigger both growth arrest and apoptosis depending on the extent and type of DNA damage inflicted on the cell [3,4]. Over $50 \%$ of human cancers in general and up to $70 \%$ of HNSCC have been reported to have $p 53$ gene aberrations [5]. Furthermore, mutations in the $p 53$ gene are present in approximately $20 \%$ of premalignant head and neck lesions suggesting a role for p53 in the early stages of HNSCC development [6]. Although $p 53$ mutations appear to arise less frequently in primary prostate cancer [7], they occur frequently in metastatic disease [8]. Finally, in most cases, $p 53$ gene therapy appears to work in HNSCC and prostate cancer regardless of their $p 53$ status $[9,10]$.

\section{Clinical trials for cancer treatment: gene therapy}

Recent clinical data from studies utilizing gene therapy for the treatment of cancer have shown promising results, particularly those strategies utilizing either adenoviral delivered wild-type p53 or replication-competent adenoviruses [11-14]. Adenoviruses are double-stranded DNA viruses that are widely used as vectors for gene therapy due to their superior ability to transfer genes in vivo, as well as their broad tissue tropism [15]. In the USA, Introgen Therapeutics, Inc. has created adenoviral $p 53$ gene therapy INGN 201 (Advexin ${ }^{\circledR}$ ) that is currently undergoing clinical development for the treatment of a variety of 
cancer types, including head and neck cancer [16] and prostate cancer [10]. INGN 201 is a new investigational drug, granted designation as a Fast Track Drug Product by the US Food and Drug Administration (FDA) on September 17, 2003 after it had previously been given orphan drug status. As of June 2004, 445 patients have been treated with INGN 201 in 14 different Phase I, II and III clinical trials [17]. In three of these trials, INGN 201 was combined with chemo- or radiation therapy $[12,14,18]$. Combination therapy appears more efficacious than viral monotherapy.

China became the first country to approve commercial production of an adenoviral-based Adp53 therapy (Gendicine) for the treatment of cancer [19]. The company involved, Shenzhen Sibiono GenTech, obtained the license from the State Food and Drug Administration of China (SFDA) on October 15, 2003.

China has an estimated 250,000-300,000 new cases of HNSCC per year, with a similar number also seen in India [20]. In the USA, approximately 40,300 cases of HNSCC occur each year with 11,700 associated deaths [6]. Alcohol and tobacco are believed to be the main etiological factors in the development of HNSCC, but diet, viral infection and oral hygiene have also been suggested to play a role. Sibiono states that in their clinical trials for HNSCC, the cost per patient is US $\$ 360$ per dose and they administer 6 to 10 doses of $1 \times 10^{12}$ viral particles for a total cost of approximately US\$3600. In the USA, Introgen Therapeutics estimates that the cost for an Adp53 regimen in HNSCC is approximately US $\$ 20,000$. Clearly, the number of HNSCC patients worldwide projects an excellent commercial market for companies who successfully establish this therapeutic approach.

There is an accumulating body of evidence in both the USA and China to suggest that the $p 53$ gene therapy approach is having reasonable efficacy in patients with HNSCC. In the Sibiono trials, viral administration is by an orthotopic injection route directly into the tumor. The data from these trials is still unpublished as of September 2004, but was presented in abstract form at the American Society of Gene Therapy in June 2003 [21]. In both the American and Chinese gene therapy trials, inclusion of a second arm of radiation or chemotherapy led to the generalized conclusion that the combined approach is significantly more efficacious than the virus alone [18,21-26].

\section{Clinical studies of INGN 201}

Clinical studies of INGN 201 in HNSCC in humans alone, or in combination with DNAdamaging agents, are currently being carried out. Generally, adenovirally-delivered $p 53$ has been observed to be safe and well tolerated. However, early studies demonstrated limited antitumor responses $[23,25,27,28]$. For example, in a Phase I study of 33 patients with bulk HNSCC, significant clinical response was observed in nine of 18 clinically evaluable patients. Interestingly, systemic Adp53 DNA was present transiently, for less than $48 \mathrm{~h}$, and was detected in blood, urine and sputum. In another study, intratumoral Adp53 was administered to 30 patients with recurrent HNSCC, and the results demonstrated clinical activity characterized by apoptosis, inflammation, increased $p 53$ expression and necrosis of the tumor tissue. In another Phase II trial using INGN 201 as single-agent therapy for patients with recurrent HNSCC, five out of $90(6 \%)$ of individuals evaluated achieved a complete or partial response, where the disease was stabilized in another $20 \%$ of the patients [11,29]. However, this strategy did not result in the complete eradication of tumors. Later studies demonstrated that combination therapy with chemotherapeutic drugs or ionizing radiation significantly enhanced the therapeutic response to wild-type p53 gene therapy [26,29].

\section{Conditionally replicative adenovirus therapy of HNSCC}

Another strategy directed at the p53 pathway, although more a viral therapy approach, is the ONYX-015 trial for HNSCC. This adenovirus expresses E1A but lacks E1B 55K and has been shown to replicate within tumor cells lacking wild-type $p 53$, resulting in their lysis [30]. Interaction of E1B $55 \mathrm{~K}$ with $p 53$ has been shown to inactivate $p 53$ allowing viral replication. Therefore, it has been suggested that E1B $55 \mathrm{~K}$-deleted ONYX-015 would be unable to degrade $p 53$ in normal cells and thus be unable to replicate efficiently, while cancer cells lacking $p 53$ function would be susceptible to viral replication and subsequent cytolysis [31].

Phase I and II clinical trials were carried out using intratumoral injection of ONYX-015 into recurrent and refractory head and neck carcinomas [11,13,32,33]. Selective intratumoral replication was shown in most HNSCC biopsies. Normal cells were not significantly affected. ONYX-015 has been used to treat over 258, including 99 
HNSCC patients, in approximately 15 clinical trials, ranging from Phase I to II [13]. Although no maximally tolerated doses (MTDs) have been identified, the virus has been well tolerated at doses up to $2 \times 10^{12}$ particles administered through intratumoral, intraperitoneal, hepatic arterial and intravenous routes. Viral replication was tumor selective, but replication varied between tumor types, as they differ in permissiveness for viral infection and replication. The associated adverse events (AEs) were flu-like in nature and were independent of dose [32-34]. Although the safety of ONYX-015 has been established, the single-agent efficacy remains limited. In two Phase II trials involving patients with recurrent head and neck cancer, even aggressive treatment with several needle passes a day for 5 days only resulted in an unconfirmed response rate of $14 \%$ [33]. However, clinical data has shown that the efficacy of ONYX-015 is greatly increased through combination with chemotherapeutic agents, such as irinotecan (CPT-11) or 5-fluorouracil (5-FU) [34]. Further studies are necessary to determine whether there is a potential synergy between these two treatments.

There is controversy regarding $p 53$-dependent specificity of ONYX-015. Initially it was reported that the virus specifically targeted $p 53$ mutant tumor cells in vitro and in vivo. However, several tumor cell lines having normal $p 53$ gene status were also found to be sensitive to ONYX-015 and it was suggested this could be due to other mechanisms of loss of $p 53$ function besides mutations [35]. ONYX-015 lacks E1B $55 \mathrm{~K}$, however, it still contains E1A, which has been shown to have potent tumor suppressive properties [36]. Moreover, E1A has been shown to sensitize cancer cells but not normal cells to chemotherapy, and this effect was independent of $p 53$ in some models [37]. In a Phase I clinical trial, the adenovirus $E 1 A$ gene was delivered via intratumoral injection by lipoplex, a cationic DC-Chol:DOPE liposome-based delivery system (DCC-E1A) in patients with recurrent head and neck cancer, and was found to be safe [38]. Another liposome-based gene therapy system for breast, and head and neck cancer xenografts also involved the use of E1A [39]. It is therefore possible that the tumor suppressive properties of ONYX-015 are at least partly mediated by the presence of E1A.

In a different viral approach, a highly purified strain of Newcastle disease virus, PV701, selectively killed tumor cells with defects in the interferon (IFN)-mediated antiviral response [16]. Such defects are commonly found in a variety of tumor types, as they confer growth and survival advantages to the tumor cells. A total of three Phase I trials using systemic administration of PV701 as a single agent have been performed in order to characterize and improve the management of AEs, and to optimize dose and dosing schedules for future Phase II trials [16]. PV701induced AEs include flu-like symptoms, tumorsite-specific effects and AEs resulting from administration [40]. The first dose of PV701 led to a decrease in toxicity, and this desensitization is an important aspect of PV701 clinical development.

\section{Clinical trials for cancer treatment: oncolytic viruses in prostate cancer}

The prostate represents an excellent system for the development of gene therapy, since the primary tumor site is easily accessible, the prostate is an expendable organ, and a reliable circulating marker for the disease, prostate-specific antigen (PSA), is readily available [40]. A variety of human cancers are currently being treated with adenoviral delivered $p 53$ oncolytic viruses, with promoters including prostate-specific probasin promoter [41]. Another adenovirus, CV706 is a replication-competent, E3-deleted, cytolytic Ad5-based virus that uses PSA promoter-regulated replication. CV706 has been shown to selectively kill human prostate cancer cells in preclinical models [15]. DeWeese and colleagues performed a Phase I clinical trial using intraprostatic delivery of CV706 to determine the safety and antitumor activity in patients with locally recurrent prostate cancer following radiation therapy [15]. The results of this study showed that CV706 delivered through intraprostatic injection was safe and not associated with any irreversible grade 3 or 4 toxicity. Furthermore, none of the patients experienced higher than grade 1 elevation of liver transaminase. The study also provided evidence of CV706 activity. Serum PSA levels, which are known markers of disease activity and burden, were reduced in all patients. There was evidence of a dose-response relationship, as those patients receiving the highest doses of CV706 had greater reductions of serum PSA levels. Of the five out of 25 patients (25\%) with a $50 \%$ or greater reduction in serum PSA, four achieved a partial recovery sustained for at least 4 weeks, with a mean and median duration of 6.6 months. These results suggest that CV706 treatment has potential for disease stabilization. 


\section{Figure 1. Ceramide metabolism in normal and cancerous cells.}

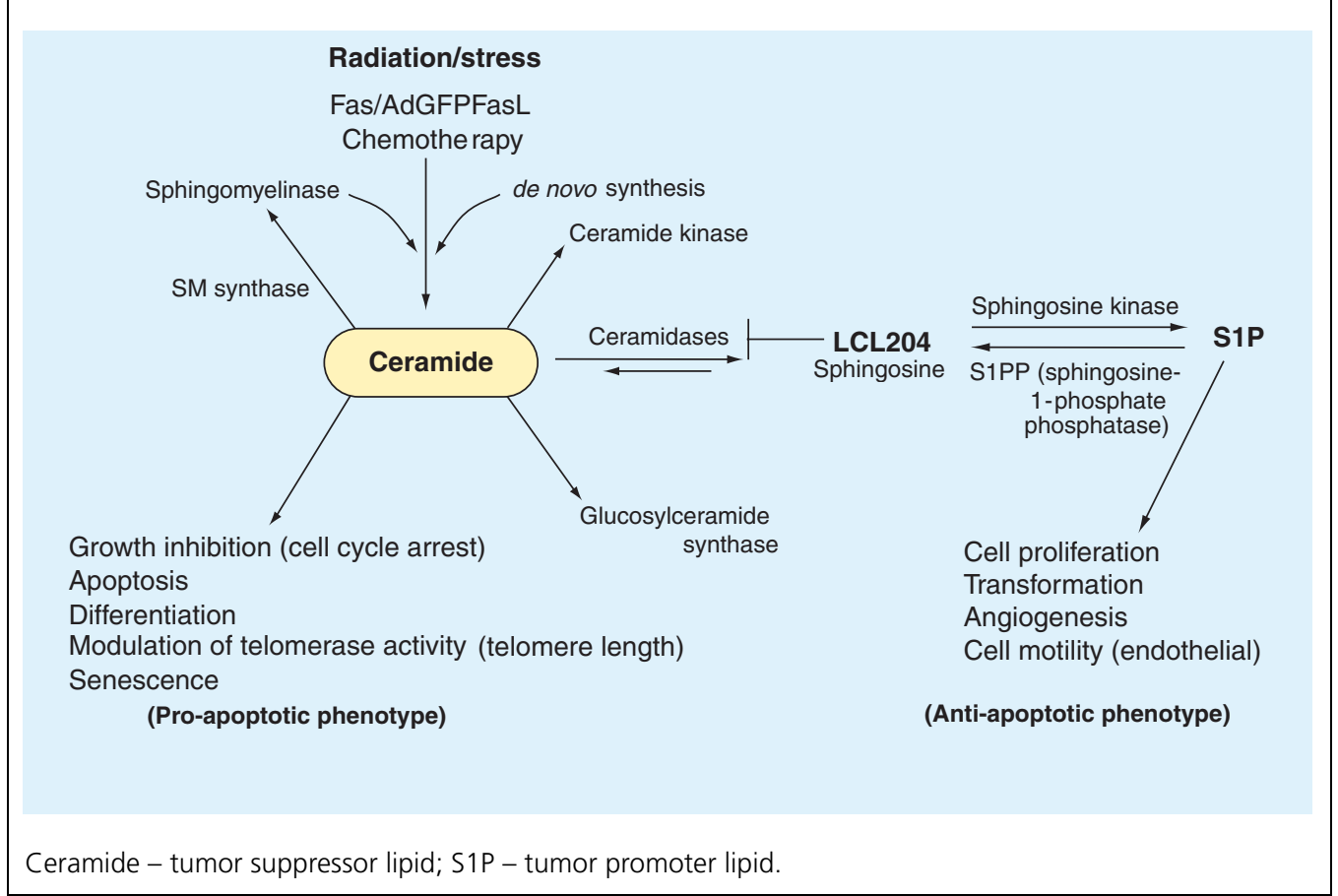

\section{Prodrug therapy of prostate cancer}

A different gene therapy approach involving prodrug bystander therapy has been directed towards the treatment of prostate cancer. Freytag and colleagues [42] have recently reported the results of a Phase I clinical trial involving intraprostatic injections of a lytic, replication-competent adenovirus (Ad5-CD/TKrep) that delivers a cytosine deaminase $(\mathrm{CD})$ and herpes simplex virus-1 thymidine kinase (TK) fusion gene to malignant cells [11]. Both CD and TK, when expressed, cause cancer cells to become more sensitive to certain pharmacological agents and radiation. Vector delivery was followed by 1 or 2 weeks of prodrug therapy with 5 -fluorocytosine (5-FC) and ganciclovir (GCV). Significantly, $94 \%$ of the AEs were grade 1 or 2 , and all hepatotoxic events were transient in nature. The results of this trial also demonstrated biological activity, as seen by decreases in serum PSA levels and histological evidence of tumor destruction. This double suicide gene therapy approach has potential as an effective adjuvant to radiation treatment and chemotherapy.

\section{Stress-regulated ceramide regulation \& deregulation in prostate cancer}

Cancer cells in a growing tumor are subjected to multiple modes of stress including anoxia, nutrient deprivation and immune attack. Such insults lead to induction of ceramide, which in normal cells results in cell cycle arrest and/or cell death (apoptosis or necrosis) [43]. However, the constantly changing genomes of cancer cells and the selective pressures involved in successful tumor formation generate escape mechanisms to surmount this homeostatic control point. One way to escape is to ensure that if ceramide is upregulated by stress, it is also rapidly removed by sphingolipid metabolizing enzymes. This appears to be occurring in prostate tumors, which when analyzed for acid ceramidase (AC) expression, revealed that $41.6 \%$ of the samples showed increased levels of acid ceramidase mRNA [44]. The percentage expressing AC increased with Gleason grade, thus, in prostate cancer a significant fraction of tumors have the potential to survive stress-induced ceramide by overexpression of AC. Although other enzymes exist to remove ceramide (Figure 1) [43], AC seems to be highly relevant in human prostate [44].

\section{Ceramidase}

The family of ceramidases includes acid 8p22p21.3, neutral 10q11.21 and alkaline 19p13.3 species [44-48]. Human acid ceramidase maps to 8 p 22 , a region of chromosome 8 frequently deleted in prostate cancer [49]. Ceramidases catalyze the deacylation of ceramide yielding sphingosine and free fatty acids [46]. 
Figure 2. A dose-response curve to acid ceramidase inhibitors LCL102 and LCL204.

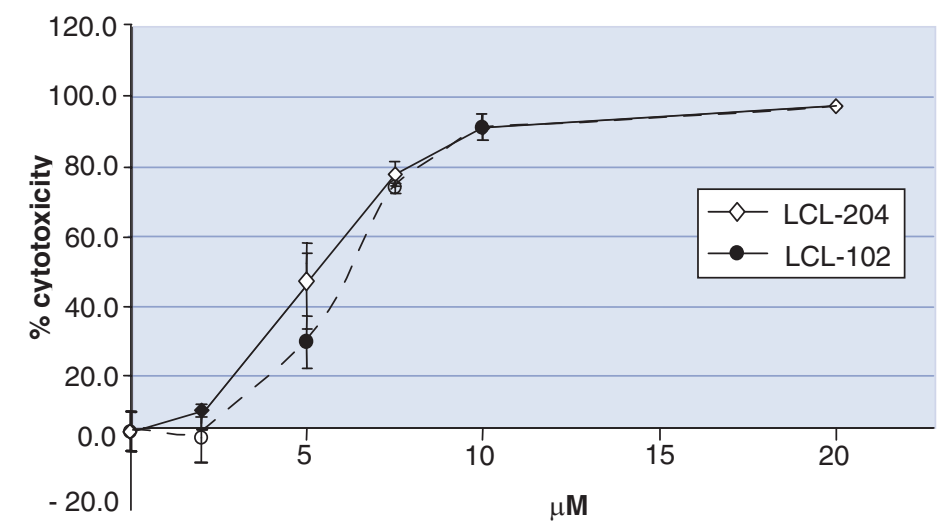

DU145 ( $1 \times 104)$ seeded O/N in 2\% FBS RPMI. The next day media was changed LCL102 or LCL204 was added in $<0.1 \%$ ethanol for $24 \mathrm{~h}$ and cytotoxicity was analyzed by CellTiter $96^{\circledR}$ AQueous One Solution Cell Proliferation Assay (MTS, Promega). Each point in both curves is normalized to vehicle alone treated cells.

Sphingosine-1-phosphate ( $\mathrm{S} 1 \mathrm{P})$ is the product of phosphorylation of sphingosine, by sphingosine kinase 1 or 2 . S1P is broken down by sphingosine-phosphate phosphatase and/or by sphingosine-phosphate lyase. S1P binds to

Figure 3. Sensitization of DU145 cells to AdGFPFasL virus by LCL-204 over $24 \mathrm{~h}$.

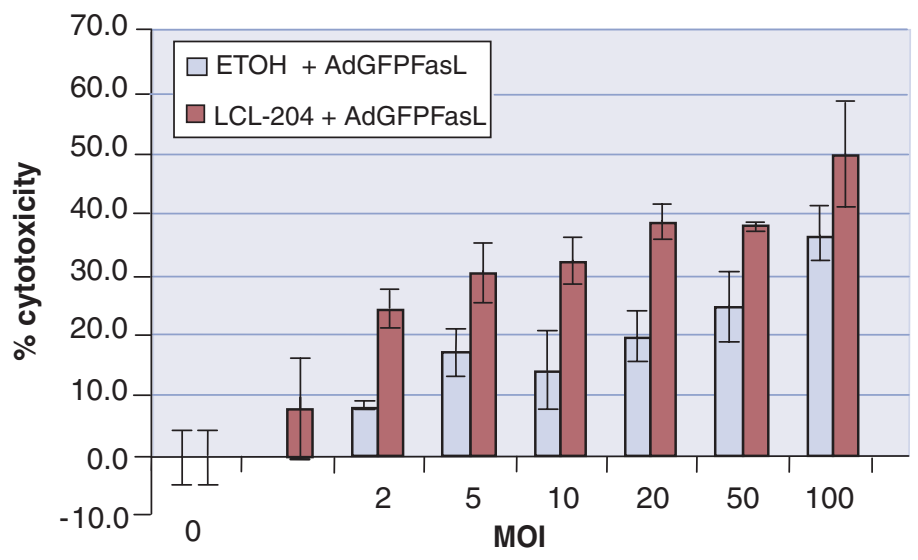

DU145 cells were seeded in $1 \times 104$ cells per well in 96-well plate in $50 \mu \mathrm{l} \mathrm{RPMI}$ supplemented with $2 \%$ FBS in $50 \mu \mathrm{l}$. Then $50 \mu \mathrm{l}$ of media was added with LCL204 to reach a total volume of $100 \mu \mathrm{l}$. Cells were incubated for $48 \mathrm{~h}$ at $37^{\circ} \mathrm{C}$ in $5 \% \mathrm{CO}_{2}$. Media was replaced with $100 \mu \mathrm{l}$ of media containing the AdGFPFasLTET at the indicated $\mathrm{MOI}$ and cells were incubated for $24 \mathrm{~h}$. The CellTiter $96^{\circledR}$ Aqueous One Solution Cell Proliferation Assay (MTS, Promega) was used to calculate the cytotoxicity following the manufacturers protocol.

ETOH: Ethanol; FBS: Fetal bovine serum; MOI: Multiplicity of infection. members of the G-protein-coupled receptor family, namely the Edg receptors, recently renamed S1P receptors [50]. It then mediates several biologic activities. These include mitogenesis, cell survival, adherence junction formation, endothelial cell morphogenesis into capillary-like structures, and angiogenesis, i.e., it is antiapoptotic [43]. Conversely, blocking acid ceramidase function may reverse this process by increasing ceramide levels and producing a pro-apoptotic phenotype. Strelow and colleagues support this finding [51]. In their report, they document that overexpression of acid ceramidase protects tumor cells from TNF- $\alpha$-induced cell death.

\section{FasL-resistant phenotypes}

Studies from the authors' laboratory have previously shown that adenoviral-mediated delivery of a green fluorescent protein (GFP) FasL fusion protein overcomes resistance to Fasmediated apoptosis in DU145 prostate cancer (PCa) cells [52]. It was also determined that this resistance is due to overexpression of antiapoptotic proteins such as cFLIPs [53]. As discussed earlier, acid ceramidase is upregulated in PCa cell lines PC-3, LNCaP, and DU145, as well as $41.6 \%$ of primary prostate tumors studied [44]. Treating DU145 cells with acid ceramidase inhibitors LCL102 and LCL204, results in dose and time-dependent cell death at micromolar concentrations (Figure 2). The authors' recent work has focused on this by examining the mechanism of action of LCL204 and how it appears to sensitize cancer cells to both AdGFPFasL and to exogenous Fas signals induced by $\mathrm{CH}-11$, FasL (Alexis) and apoptotic vesicles and thus creating a tumor more susceptible to bystander-mediated events. The authors' studies reveal the initiation of powerful lysosome-mediated signaling that appears to work through the intrinsic (Type II) mitochondrial pathway to apoptosis. Preclinical studies are underway to move this therapy into a Phase I clinical trial. These studies are important due to the delivery limitations widely observed in cancer gene therapy trials particularly using replication incompetent viruses [54-56].

\section{Overcoming gene delivery limitations}

One of the problems with cancer gene therapy as it is currently practiced is the issue of delivery of gene therapy vectors to every tumor cell in order to affect the death of the tumor [54,56]. This can be overcome to an extent if the therapy induces a 
bystander activity within the tumor bed [54,57]. These studies demonstrate, following administration of AdGFPFasL, that bystander activity is mediated by apoptotic vesicles expressing FasL [57].

Although it is unknown if PCa cells in vivo are resistant to FasL-mediated apoptosis, Hyer and colleagues have shown that in vitro, certain types of cell lines including DU145 PCa cells are highly resistant to the exogenous application of either FasL, monoclonal antibodies that are FasL agonists or bystander vesicles [53]. This led to attempts to devise molecular approaches that would sensitize tumor cells to the bystander effects in order to achieve multiple cell killing in a solid tumor in which, at best, $30 \%$ of the cells are infected by the virus. The authors' laboratory has been able to demonstrate that acid ceramidase inhibitors appear to sensitize the cells to this type of cell death (Figure 3). This led to an in vivo experiment in which prostate cancer xenografts, in this case DU145 cells, were grown in nude

\section{Executive summary}

The potential \& the problems

- There are ample numbers of targets for gene therapy, but the science of delivery needs further development.

p53 \& its family members

- The most frequently observed genetic defect in head and neck squamous cell cancer (HNSCC) are mutations in p53. Early lesions in p53 suggest a role in premalignancy.

- In prostate cancer (PCa), p53 mutations appear more associated with metastatic disease.

- Adp53 therapy works in both HNSCC and PCa, regardless of p53 status.

\section{Clinical trials for cancer}

- Results from clincal trials look promising. There are two leading candidate viruses for delivery of $p 53$, Gendicine and Advexin.

- Gendicine has approval from the State Food and Drug Administration of China (SFDA).

- Advexin has US Food and Drug Administration (FDA) fast track status.

- There is a large Asian market for these biological therapies.

- Adp53 injection coupled with chemo- or radiotherapy gives the best response.

Clinical studies of INGN 201

- Clinical studies have shown that INGN 201 therapy is well tolerated.

- Single agent therapy is not as effective as combination therapy.

\section{Conditionally replicative adenovirus therapy in HNSC}

- Use of adenoviral therapy with viruses that replicate predominantly in tumors has been studied. Viruses were well tolerated but the response rates were low. Combination therapy was more effective.

\section{Clinical trials for cancer treatment: oncolytic viruses}

- Oncolytic viral therapy with a prostate-specific adenovirus has been carried out with no grade limiting toxicity. Limited efficacy was observed

\section{Pro-drug therapy of prostate cancer}

- Bystander therapy using a pro-drug approach has potential as an effective adjuvant to radiation or chemotherapy.

\section{Stress-related ceramide regulation}

- Cellular stress will induce formation of the tumor suppressor lipid ceramide. Ceramide induces cell cycle arrest and apoptosis. At least $42 \%$ of primary prostate cancers overexpress acid ceramidase, which metabolizes ceramide to sphingosine. This is believed to lead to an anti-apoptotic phenotype and improved cancer cell survival.

\section{Fas ligand-resistant phenotypes}

- A large percentage of HNSSC and PCa cells are resistant to Fas ligand (FasL)-induced apoptosis. However, if FasL is expressed intracellularly, resistant tumor cells undergo apoptosis.

- Resistance to FasL can be reduced using an acid ceramidase inhibitor.

- When combined with adenoviral-mediated FasL expression, a higher percentage of cells undergo apoptosis at a lower dose of virus.

\section{Conclusions \& future perspective}

- Gene therapy trials started in 1990. Success is already seen for somatic cell therapy of terminal illnesses such as severe combined immunodeficiencies.

- Cancer gene therapy is the most widely applied therapy with an estimated 4000 patients having received treatment.

- The most successful cancer gene therapy seems to occur in combination with current standards of care, such as radiation or chemotherapy. Most of these therapies modify intracellular ceramide metabolism.

- It is the authors' belief that combining gene therapy with drugs designed to increase intracellular ceramide will translate successfully to the clinic and be efficacious in both PCa and HNSCC treatment protocols. 
mice and treated sequentially with the acid ceramidase inhibitor LCL204 followed by the AdGFPFasL virus. The efficacy of this approach was clearly demonstrated [Manuscript in Preparation]. The importance of this is twofold: first, orthotopic administration of the AdGFPFasL virus does not result in any systemic toxicity as judged from the published data [58], second, the administration of up to $75 \mathrm{mg} / \mathrm{kg}$ of LCL2 24 has no observable effect on the animal [Unpublished Data]. When combined, these two molecules effectively reduce the tumor burden and yet, at the same time, leave the animal in overall good health. Thus, a potentially promising gene therapy/small molecule approach for treatment of solid tumors is under development.

\section{Conclusions \& future perspective}

It is generally believed that in 1967 Joshua Lederberg and Edward Tatum were the first to provide a framework for performing gene therapy [59]. However, the first sanctioned gene therapy trial did not take place until September 14, 1990 at the National Institute of Health
[60,102]. Although failures such as at Institute for Human Gene Therapy at the University of Pennsylvania, and more recently the Leukemialike syndrome in the SCID-X1 trial, make the biggest headlines, we are beginning to see success in the field, particularly in cancer trials that use Adp53 in combination with radiation or chemotherapy [12,37]. In the future, these combined approaches will become more common. A unifying theme of combined therapy to date that needs emphasis is that drugs such as cisplatin, 5-FU, the acid ceramidase inhibitor LCL204, or radiation, all have one thing in common: they elevate intracellular levels of the tumor suppressor lipid ceramide [61,62]. It is the author's contention that combining gene therapy with agents that generate ceramide and shift cancer cells to a pro-apoptotic phenotype will prove to be translatable to the cancer clinic.

\section{Acknowledgements}

Supported by 1R24 CA82933-01, HCC/DOD N6311601MD10004, NIH 5 R01 CA69598 and PO1 CA97132-01A1.

\section{Bibliography}

Papers of special note have been highlighted as either of interest $(\bullet)$ or of considerable interest $(\bullet)$ to readers.

1. Evan GI, Vousden, KH: Proliferation, cell cycle and apoptosis in cancer. Nature 411(6835) 342-348 (2001).

2. Ko LJ, Prives C: $p 53$ : puzzle and paradigm. Genes Dev. 10(9), 1054-1072 (1996).

3. Levine AJ: $p 53$, the cellular gatekeeper for growth and division. Cell 88(3), 323-331 (1997).

4. Morgan SE, Lovly C, Pandita TK, Shiloh Y, Kastan MB: Fragments of ATM which have dominant-negative or complementing activity. Mol. Cell. Biol. 17(4), 2020-2029 (1997).

5. Blons H, Laurent-Puig P: TP53 and head and neck neoplasms. Hum. Mutat. 21(3), 252-257 (2003).

6. Boyle JO, Hakim J, Koch W et al: The incidence of $p 53$ mutations increases with progression of head and neck cancer. Cancer Res. 53(19), 4477-4480 (1993).

7. Brooks J, Bova G, Ewing C et al: : An uncertain role for $p 53$ gene alterations in human prostate cancers. Cancer Res. 56(16) 3814-3822 (1996).

8. Stapleton A, Timme T, Gousse A et al: Primary human prostate cancer cells harbouring $p 53$ mutations are clonally expanded in metastases. Clin. Cancer Res. 3(8), 1389-1397 (1997).

9. Colletier PJ, Ashoori F, Cowen D et al: Adenoviral-mediated $p 53$ transgene expression sensitizes both wild type and null $p 53$ prostate cancer cells in vitro to radiation. Int. J. Radiat. Oncol. Biol. Phys. 48 (5), 1507-1512 (2000).

10. Merritt JA, Roth JA, Logothetis CJ: Clinical evaluation of adenoviral-mediated $p 53$ gene transfer: review of INGN 201 studies. Semin. Oncol. 28(5 Suppl. 16), 105-114 (2001).

- Good review of the Introgen Therapeutics Adp53 trials.

11. Kirn D: Oncolytic virotherapy for cancer with the adenovirus d11520 (Onyx-015): results of Phase I and II trials. Expert Opin. Biol. Ther. 1(3), 525-538 (2001).

- Good review of oncolytic adenoviral trials.

12. Collis SJ, Khater K, DeWeese, TL: Novel therapeutic strategies in prostate cancer management using gene therapy in combination with radiation therapy. World J. Urol. 21(4), 275-289 (2003).

13. Lin E, Nemunaitis J: Oncolytic viral therapies. Cancer Gene Thmer. 11(10), 643-664 (2004).

-. Most recent review of oncolytic virus approach.

14. Swisher SG, Roth JA, Komaki R et al: Induction of $p 53$-regulated genes and tumor regression in lung cancer patients after intratumoral delivery of adenoviral $p 53$ (INGN 201) and radiation therapy. Clin. Cancer Res. 9(1), 93-101 (2003).

15. DeWeese TL, van der Poel H, Li S et al: A Phase I trial of CV706, a replicationcompetent, PSA selective oncolytic adenovirus, for the treatment of locally recurrent prostate cancer following radiation therapy. Cancer Res. 61(20), 7464-7472 (2001).

- Describes use of prostate-targeted oncolytic virus.

16. Lorence RM, Pecora AL, Major PP et al: Overview of Phase I studies of intravenous administration of PV701, an oncolytic virus. Curr. Opin. Mol. Ther. 5(6), 618-624 (2003).

17. Zumstein L, Call D, Merritt J, Sobol RE, Menander, K: Safety of adenoviral vectors: results of clinical investigations in 445 cancer patients treated with Advexin ${ }^{\circledR}$ (Adenoviral p53) gene therapy in American Society of Cancer Gene Therapy Vol. Abstr. 1007, IN, USA (2004).

18. Nemunaitis J, Swisher SG, Timmons T et al:: Adenovirus-mediated $p 53$ gene transfer in sequence with cisplatin to tumors of patients with non-small-cell lung cancer. J. Clin. Oncol. 18(3), 609-622 (2000).

19. Fox JL: China approves first gene therapy. Nature Biotechnol. 22(1), 3-4 (2004). 
20. Vokes EE, Weichelbaum RR, Lippman SM, Hong WK: Head and neck cancer. New Engl. J. Med. 328, 84-194 (1993).

21. Peng Z, Han D, Zhang $S$ et al.: Clinical evaluation of safety and efficacy of intratumoral administration of a recombinant adenoviral- $p 53$ anticancer agent (Genkaxin $\left.{ }^{\circledR}\right)$. In The American Society of Gene Ther. Vol. 7(Suppl. 1), Verma IM (Ed), Molecular Therapy, Elsevier, Inc., Washington DC, USA, S422 (2003).

22. Sasaki R, Shirakawa T, Zhang ZJ et al:: Additional gene therapy with Ad5CMV-p 53 enhanced the efficacy of radiotherapy in human prostate cancer cells. Int. J. Radiat. Oncol. Biol. Phys. 51(5), 1336-1345 (2001).

23. Clayman GL: The current status of gene therapy. Semin.Oncol. 27(4 Suppl. 8), 39-43 (2000).

- Good review of gene therapy status.

24. Roth J, Cristiano R: Gene therapy for cancer: what have we done and where are we going? J. Natl Cancer Inst. 89(1), 21-39 (1997).

25. Clayman GL, Frank DK, Bruso PA Goepfert H: Adenovirus-mediated wild type $p 53$ gene transfer as a surgical adjuvant in advanced head and neck cancers. Clin. Cancer Res. 5(7), 1715-1722 (1999).

26. Gurnani M, Lipari P, Dell J, Shi B, Nielsen LL: Adenovirus-mediated $p 53$ gene therapy has greater efficacy when combined with chemotherapy against human head and neck, ovarian, prostate, and breast cancer. Cancer Chemother. Pharmacol. 44(2), 143-151 (1999).

27. Xi S, Grandis JR: Gene therapy for the treatment of oral squamous cell carcinoma. J. Dent. Res. 82(1), 11-16 (2003).

28. Clayman GL, el-Naggar AK, Lippman SM et al:: Adenovirus-mediated $p 53$ gene transfer in patients with advanced recurrent head and neck squamous cell carcinoma. $J$. Clin. Oncol. 16(6), 2221-2232 (1998).

29. Goodwin WJ, Esser D, Clayman GL, Al E: Randomized Phase II study of intratumoral injection of two dosing schedules using a replication-deficient adenovirus carrying the p53 gene (AD5CMV-P53) in patients with recurrent/refractory head and neck cancer. Proc. Am. Soc. Clin. Oncol. 18, 445a (1999).

30. Heise C, Williams A, Olesch J, Kirn D: Efficacy of a replication-competent adenovirus (ONYX-015) following intratumoral injection: intratumoral spread and distribution effects. Cancer Gene Ther 6, 499-504 (1999).

31. Heise C, Ganly I, Kim YT et al:: Efficacy of a replication-selective adenovirus against ovarian carcinomatosis is dependent on tumor burden, viral replication and $p 53$ status. Gene Ther. 7(22), 1925-1929 (2000).

32. Ganly I, Kirn D, Eckhardt G et al.: A Phase I study of Onyx-015, an E1B attenuated adenovirus, administered intratumorally to patients with recurrent head and neck cancer. [Erratum appears in Clin. Cancer. Res. 6(5), 2120 (2000). Note: Eckhardt SG [corrected to Eckhardt G]. Clin. Cancer Res. 6(3), 798-806 (2000).

33. Nemunaitis J, Ganly I, Khuri F et al.: Selective replication and oncolysis in $p 53$ mutant tumors with ONYX-015, an E1B$55 k D$ gene-deleted adenovirus, in patients with advanced head and neck cancer: a Phase II trial. Cancer Res. 60(22), 6359-6366 (2000).

34. Nemunaitis J, Cunningham C, Tong AW et al: : Pilot trial of intravenous infusion of a replication-selective adenovirus (ONYX015) in combination with chemotherapy or IL-2 treatment in refractory cancer patients. Cancer Gene Ther. 10(5), 341-352 (2003).

35. Heise C, Kirn, DH: Replication-selective adenoviruses as oncolytic agents. J. Clin. Invest. 105(7), 847-851 (2000).

36. Mymryk JS: Tumor suppressive properties of the adenovirus $5 E 1 A$ oncogene. Oncogene 13(8), 1581-1589 (1996)

37. Khuri FR, Nemunaitis J, Ganly I et al:: A controlled trial of intratumoral ONYX-015, a selectively-replicating adenovirus, in combination with cisplatin and 5 fluorouracil in patients with recurrent head and neck cancer [see comment]. Nature Med. 6(8), 879-885 (2000).

38. Yoo GH, Hung MC, Lopez-Berestein G et al: : Phase I trial of intratumoral liposome E1A gene therapy in patients with recurrent breast and head and neck cancer. Clin. Cancer Research 7(5), 1237-1245 (2001).

39. Ueno NT, Bartholomeusz C, Xia W et al.: Systemic gene therapy in human xenograft tumor models by liposomal delivery of the E1A gene. Cancer Res. 62(22), 6712-6716 (2002).

40. Pecora AL, Rizvi N, Cohen GI et al:: Phase I trial of intravenous administration of PV701, an oncolytic virus, in patients with advanced solid cancers [see comment]. $J$. Clin. Oncol. 20(9), 2251-2266 (2002).

- Clinical trial of oncolytic Newcastle Disease Virus.

41. Yu DC, Chen Y, Dilley J et al:: Antitumor synergy of CV787, a prostate cancer-specific adenovirus, and paclitaxel and docetaxel. Cancer Res. 61(2), 517-525, (2001).
42. Freytag SO, Khil M, Stricker $\mathrm{H}$ et al.: Phase I study of replication-competent adenovirus-mediated double suicide gene therapy for the treatment of locally recurrent prostate cancer. Cancer Res. 62(17), 4968-4976 (2002).

- Study of bystander-prodrug therapy in prostate cancer.

43. Ogretmen B, Hannun YA: Biologically active sphingolipids in cancer pathogenesis and treatment. Nature Rev. Cancer 4(8), 604-616 (2004).

- $\quad$ Excellent in-depth review of ceramide signalling in cancer.

44. Seelan RS, Qian C, Yokomizo A et al.: Human acid ceramidase is overexpressed but not mutated in prostate cancer. Genes Chrom. Cancer 29(2), 137-146 (2000).

- Raises the importance of ceramide metabolism in prostate cancer.

45. Mao CG, Xu RJ, Szulc ZM et al: : Cloning and characterization of a novel human alkaline ceramidase - a mammalian enzyme that hydrolyzes phytoceramide. J. Biol. Chem. 276(28), 26577-26588 (2001)

46. Koch J, Gartner S, Li CM et al: Molecular cloning and characterization of a full-length complementary DNA encoding human acid ceramidase. Identification Of the first molecular lesion causing Farber disease. J. Biol. Chem. 271(51), 33110-33115 (1996).

47. El Bawab S, Bielawska A, Hannun YA: Purification and characterization of a membrane-bound nonlysosomal ceramidase from rat brain. J. Biol. Chem. 274(39), 27948-27955 (1999).

48. El Bawab S, Roddy P, Qian T et al.: Molecular cloning and characterization of a human mitochondrial ceramidase. J. Biol. Chem. 275(28), 21508-21513 (2000).

49. Dong JT: Chromosomal deletions and tumor suppressor genes in prostate cancer. Cancer Met. Rev. 20(3-4), 173-193 (2001).

50. Lee MJ, Van Brocklyn JR, Thangada S et al.: Sphingosine-1-phosphate as a ligand for the G protein-coupled receptor EDG-1. Science 279(5356), 1552-1555 (1998).

51. Strelow A, Bernardo K, Adam-Klages S et al.: Overexpression of acid ceramidase protects from tumor necrosis factorinduced cell death. J. Exp. Med. 192(5), 601-612 (2000).

- Interesting confirmatory study for the role of ceramide in cancer apoptosis.

52. Hyer ML, Voelkel-Johnson C, Rubinchik S, Dong J, Norris JS: Intracellular Fas ligand expression causes Fas-mediated apoptosis in human prostate cancer cells resistant to 
monoclonal antibody-induced apoptosis. Mol.Ther. 2(4), 348-358 (2000).

- Demonstrates many prostate cancer cell lines are resistant to exogenous FasL signaling.

53. Hyer ML, Sudarshan S, Kim Y et al:: Downregulation of c-FLIP sensitizes DU145 prostate cancer cells to Fasmediated apoptosis. Cancer Biology Ther. 1(4), 348-358 (2002).

54. Norris JS, Hyer ML, Voelkel-Johnson C et al: : The use of Fas Ligand, TRAIL and Bax in gene therapy of prostate cancer. Curr. Gene Ther. 1(1), 123-136 (2001).

- Reviews bystander effects and gene therapy.

55. Norris JS, Holman DH, Hyer ML et al: Ceramide, Ceramidase and FasL Gene Therapy in Prostate Cancer. In: Death Receptors in Cancer Therapy, Vol. El-Deiry WS (Ed.), Humana Press, Inc., NJ, USA (2004) In Press.

-• Reviews ceramides and FasL in cancer therapy.

56. Holman DH, Hyer ML, El-Zawahry AM, Keller GM \& Norris JS. Pro-apoptotic Strategy in Cancer Gene Therapy. In Cancer Gene Therapy (Eds.) Curiel DT, Douglas J Humana Press, Inc., NJ, USA (2003).

57. Hyer ML, Sudarshan S, Schwartz DA et al:: Quantification and characterization of the bystander effect in prostate cancer cells following adenovirus-mediated FasL expression. Cancer Gene Ther. 10(4), 330-339 (2003).
58. Rubinchik S, Wang D, Yu H et al:: A complex adenovirus vector that delivers FASL-GFP with combined prostate-specific and tetracycline-regulated expression. Mol. Ther. 4(5), 416-426 (2001).

59. Tatum EL: Molecular Biology, Nucleic Acids, and the Future of Medicine. In Reflections on Research and the Future of Medicine Lyght CE (Ed.), McGraw-Hill, NY, USA. 31-49 (1967).

60. Blaese RM, Culver KW Miller, AD et al:: T lymphocyte-directed gene therapy for ADASCID: initial trial results after 4 years. Science 270(5235), 475-480 (1995).

- Historically significant - first gene therapy trial.

61. Hannun YA, Luberto C. Ceramide in the eukaryotic stress response. Trends Cell Biol. 10(2), 73-80 (2000).

62. Hannun YA: Functions of ceramide in coordinating cellular responses to stress. Science 274(5294) 1855-1859 (1996).

\section{Websites}

101.

http://p53.curie.fr/p53\%20site\%20version $\% 202.0 / \mathrm{p} 53 \% 20$ in $\% 20$ cancer/p53_databa seANAL.html

(Accessed January 2005)

102. www.georgetown.edu/research/nrcbl/publicat ions/scopenotes/sn24.htm (Accessed January 2005)

\section{Affiliations}

- James S Norris

Department of Microbiology and Immunology, Medical University of South Carolina,

173 Ashley Avenue, Charleston, SC 29425, USA

Tel.: +18437927915

Fax: +18437924882

norrisjs@musc.edu

- Kristi L Norris

Biochemistry Section, SNB, NINDS,

Bldg 35, Room 2C917, 35 Convent Dr Room 2C 917, MSC 2704, Bethesda,

MD 20892-3704, USA

Tel.: +13014966628

Fax: +3014082707

klnorris@gwu.edu

- Thomas E Keane

Department of Urology, Medical University of South Carolina, 173 Ashley Avenue, Charleston, SC 29425, USA

Tel.: +18437921666

Fax: +18437928523

keanet@musc.edu

- Mahvash Tavassoli

Head and Neck Oncology, King's College of

London, United Kingdom

Tel.: +442078485913

Fax: +442077333877

mahvash.tavassoli@kcl.ac.uk

- David H Holman

Department of Microbiology and Immunology, Medical University of South Carolina,

173 Ashley Avenue, Charleston, SC 29425, USA

- Ahmed El-Zawahry

Department of Microbiology and Immunology, Medical University of South Carolina,

173 Ashley Avenue, Charleston, SC 29425, USA

- Jian-yun Dong

Department of Microbiology and Immunology, Medical University of South Carolina,

173 Ashley Avenue, Charleston, SC 29425, USA 